\title{
The use of novel modified endoscopic vacuum therapies in the management of a transmural rectal wall defect
}

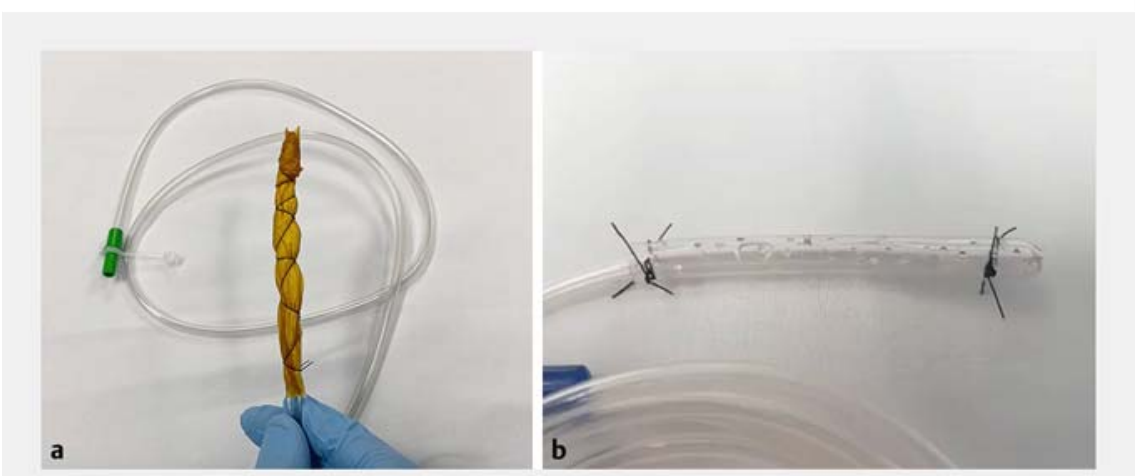

- Fig. 1 Modified endoscopic vacuum therapy systems. a Gauze and antimicrobial incise drape over a nasogastric tube (NGT). b Two NGTs and a nylon suture.
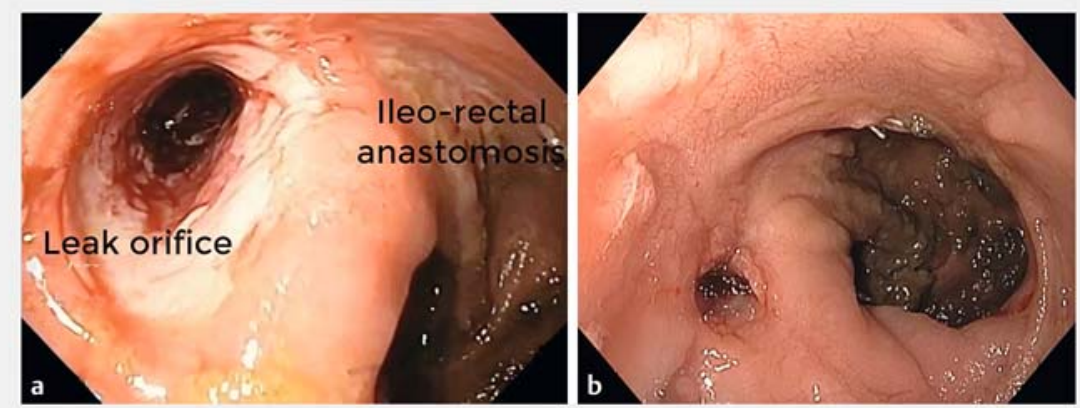

- Fig. 3 Esophagogastroduodenoscopy. a The leak at the ileorectal anastomosis. b Complete healing of the anastomotic leak after 28 days of endoscopic vacuum therapy.

Gastrointestinal transmural defects are difficult to manage and are associated with high rates of morbidity and mortality $[1,2]$. Endoscopic vacuum therapy (EVT) has developed into a safe and effective tool for intraluminal treatment of these conditions. However, the high cost of the sponge system may limit a wide spectrum of use [2-4]. In this video, we describe two cost-effective modified EVTs for treatment of transmural defects. The first technique is performed using an antimicrobial incise drape, gauze, nasogastric tube (NGT), and nylon suture. First, the antimicrobial drape is cut to fit the fenestrated portion of the NGT.
Then, several holes are made in the drape. Next, gauze is wrapped around the fenestrated portion of the NGT, and the gauze is then covered by the antimicrobial drape. Finally, the suture is used to fix the gauze and drape to the NGT ( Fig. 1 a).

The second technique requires two NGTs and nylon suture thread. First, we cut the distal end of an 18-Fr NGT, then we place a 12-Fr NGT inside the cut end of the 18-Fr NGT, ensuring that the fenestrated portions of the two NGTs do not align. Finally, the suture is used to fix the NGTs together (> Fig. 1 b).

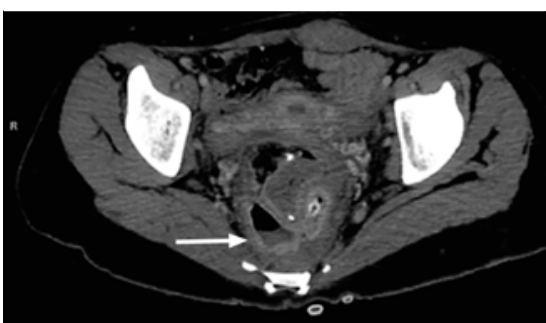

- Fig. 2 Computed tomography scan showing a leak at the ileorectal anastomosis, with an associated fluid collection (arrow).

A 29-year-old woman with familial adenomatous polyposis who had undergone proctocolectomy 2 years earlier, presented with daily fevers and rectal pain. Computed tomography scan demonstrated a leak at the ileorectal anastomosis with an associated fluid collection ( Fig.2, $>$ Fig.3a). An end-ileostomy was performed. The patient was then treated with a modified EVT system, followed by four EVT system exchanges ( Video 1). She was discharged from hospital 28 days after the initial procedure ( $>$ Fig. $\mathbf{3 b}$ ).

These novel cost-effective modified EVTs are feasible and appear to be as safe and effective as the traditional sponge EVT system.

Endoscopy_UCTN_Code_TTT_1AQ_2AG

Competing interests

Professor de Moura is a consultant for Olympus and Boston Scientific. Dr. Thompson is a consultant for Boston Scientific, USGI Medical, Fractyl Labs, Olympus, and Apollo Endosurgery. 


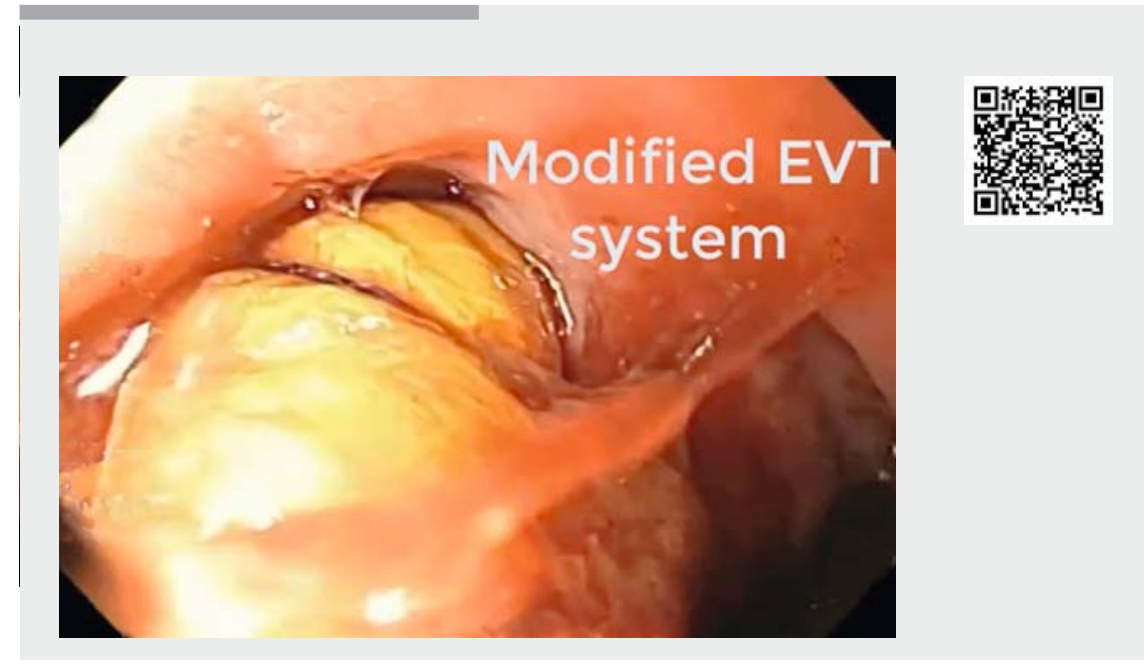

Video 1 Modified endoscopic vacuum therapy in the management of a transmural rectal wall defect.

\section{ENDOSCOPY E-VIDEOS}

https://eref.thieme.de/e-videos

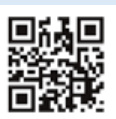

Endoscopy E-Videos is a free access online section, reporting on interesting cases and new techniques in gastroenterological endoscopy. All papers include a high quality video and all contributions are freely accessible online.

This section has its own submission website at https://mc.manuscriptcentral.com/e-videos
The authors

Diogo Turiani Hourneaux de Moura ${ }^{1}$, Epifânio Silvino do Monte Junior ${ }^{1}$, Kelly E. Hathorn ${ }^{2}$, Igor Braga Ribeiro ${ }^{1}$, Flaubert Sena de Medeiros $^{3}$, Christopher C. Thompson ${ }^{2}$, Eduardo Guimarães Hourneaux de Moura'

1 Endoscopy Unit, Gastrointestinal Department, Hospital das Clínicas da Faculdade de Medicina da Universidade de São Paulo, São Paulo, Brazil

2 Division of Gastroenterology, Hepatology and Endoscopy, Brigham and Women's Hospital, Harvard Medical School, Boston, Massachusetts, United States

3 Surgery Department, Universidade Federal de Natal, Natal, Rio Grande do Norte, Brazil

Corresponding author

\section{Diogo Turiani Hourneaux de Moura,} MD, PhD

Endoscopy Unit, Gastrointestinal

Department, Hospital das Clínicas da

Faculdade de Medicina da Universidade de São Paulo, Rua Enéas de Carvalho Aguiar 255, São Paulo, SP - 05679-065, Brazil Fax: +55-11-26617579

dthmoura@hotmail.com

\section{References}

[1] de Moura DTH, Sachdev AH, Thompson CC. Endoscopic full-thickness defects and closure techniques. Curr Treat Options Gastroenterol 2018; 16: 386-405

[2] Dos Santos NT, De Moura DTH, Galvão Neto $M$ et al. Novel laparo-endoscopic hybrid procedure to treat a disconnected Roux limb after bariatric surgery. Endoscopy 2019; 51: E341-E342

[3] de Moura DTH, Brunaldi VO, Minata M et al. Endoscopic vacuum therapy for a large esophageal perforation after bariatric stent placement. VideoGIE 2018; 3: 346-348

[4] de Moura DTH, de Moura BFBH, Manfredi MA et al. Role of endoscopic vacuum therapy in the management of gastrointestinal transmural defects. World J Gastrointest Endosc 2019; 11: 329-344

Bibliography

Endoscopy 2021; 53: E27-E28

DOI $10.1055 / a-1173-7727$

ISSN 0013-726X

published online 29.5.2020

(c) 2020. Thieme. All rights reserved.

Georg Thieme Verlag KG, Rüdigerstraße 14

70469 Stuttgart, Germany 